\title{
Molecular analysis of iduronate -2- sulfatase gene in Tunisian patients with mucopolysaccharidosis type II
}

\author{
Latifa Chkioua ${ }^{1,2^{*}}$, Souhir Khedhiri ${ }^{1,2}$, Salima Ferchichi ${ }^{1,2}$, Rémy Tcheng ${ }^{3}$, Henda Chahed ${ }^{1,2}$, Roseline Froissart ${ }^{3}$, \\ Christine Vianey-Saban ${ }^{3}$, Sandrine Laradi ${ }^{1,2}$ and Abdelhedi Miled ${ }^{1,2}$
}

\begin{abstract}
Mucopolysaccharidosis type II (MPS II, Hunter syndrome) is X-linked recessive lysosomal storage disorder resulting from the defective activity of the enzyme iduronate-2-sulfatase (IDS). Hunter disease can vary from mild to severe, depending on the level of enzyme deficiency. We report the IDS mutation and polymorphisms causing the Hunter syndrome in patients from one family in Tunisia

Patients and methods: A preliminary diagnosis was made by qualitative detection of urinary glycosaminoglycans of the suspected MPS II probands. The IDS mutation and polymorphisms were determined on these probands and their family members by amplifying and sequencing each of the exons and intron-exon junctions of IDS gene.

Results: The studied probands were homoallelic for p.R88P mutation. In addition, three known polymorphisms/ sequence variants: IVS3-16 (c.419-16 delT), T214M (c.641C > T), T146T (c.438 C > T), IVS5-87(c.709-87G > A) and one previously unknown: IVS7+38(c.1006+38T > C were identified in the MPS II patients. These are the first Tunisian MPS II patients to be genotyped.

Conclusion: The identification of these mutation and polymorphisms and their genotype-phenotype correlation should facilitate prenatal diagnosis and counseling for MPS II in Tunisia, where a very high rate of consanguinity exists.
\end{abstract}

\section{Introduction}

Mucopolysaccharidosis type II (MIM 309900) is X-linked recessive lysosomal storage disorder caused by the deficient of the enzyme iduronate 2-sulfatase (IDS, EC 3.1.6.13). This glycosidase is required for the hydrolysis of the 2-sulfate groups of the L-iduronate 2-sulfate units of dermatan sulfate and heparan sulfate [1]. Deficiency of this enzyme causes accumulation and higher urine excretion of these undegraded substrates in lysosomes leading to cell death and to the clinical manifestations of the disease. A wide spectrum of clinical severity is recognized in MPS II. Severely affected individuals usually die between 10 and 15 years of age, although some die much earlier. Individuals with mild forms of MPS II can have significant somatic disease, but reasonably normal life spans.

\footnotetext{
* Correspondence: chkioualatifa2002@yahoo.fr

1 Biochemistry Laboratory Farhat Hached Hospital, 4000 Sousse, Tunisia Full list of author information is available at the end of the article
}

The treatments for affected individuals were bone marrow [2] and enzyme replacement therapy [3]. A preliminary diagnosis was made by qualitative detection of urinary glycosaminoglycans of the suspected MPS II proband, then, confirmed by the demonstration of deficient iduronate 2 sulfatase activity in leukocytes, plasma or cultured cells. The IDS gene is situated on the telomere of the long arm of chromosome $\mathrm{X}$ at region Xq28 [4]. Two forms of IDS were identified from human placenta [5] and 2 major forms of iduronate sulfatase were purified with molecular masses of $42 \mathrm{kD}$ and $14 \mathrm{kD}$ [6]. The gene has 9 exons and produces a transcript of 1.4 that encodes a precursor protein of 550 amino acide [7]. More than 300 different mutations in the IDS gene had been reported in patients with Hunter syndrome [8] including gene rearrangements caused by recombination with the IDS2 pseudogene, deletions of certain exons or the entire IDS gene or small mutations including insertions, deletions and point mutations that created a novel splice site.

\section{C) Biomed Central}


A pseudogene IDS2 also exists $20 \mathrm{~kb}$ from the active IDS gene. This pseudogene shares homology to exon 2, intron 2 , exon 3, intron 3 and intron 7 of the IDS gene [9].

Mucopolysaccharidosis type II has two major clinical phenotypes, ranging the severe form called MPS IIA to the mild form called MPS IIB:

The severe form (MPS IIA), the child is normal at birth, and symptoms appear gradually. The diagnosis is usually referred to between 2 and 4 years. The MPS IIA patient is characterized by progressive mental retardation, physical disability, severe airway obstruction, skeletal deformities, cardiomyopathy, and, in most patients, neurologic decline. Death usually occurs at age of 15 years in most cases.

The mild form (MPS IIB), the clinical symptom appears after 10 years of age. At this age, the MPS IIB patient had normal growth and development. He had mild dysostosis radiologically, coarse facial features, flexion contractures of the elbows and shoulder joints, moderate hepatosplenomegaly and a long life span with and a long life span with minimally impaired neurological. A lack of opacification of the cornea was noted in the MPS II as opposed to the MPS I [10].

This inherited disease may constitute a relatively more important social and economic concern in Tunisia because of the prevalence of first-cousin marriages [11]. Thus, the identification of the IDS mutations causing MPS II in Tunisia is important for prenatal diagnosis in affected families. Here, we report the IDS mutation and polymorphisms causing the Hunter syndrome in patients from one family in Tunisia.

\section{Patients and methods Patients}

One family from Tunisia with MPS II was investigated. The MPS II patients were diagnosed in paediatric department of center Tunisia.

This family gave birth for 3 affected children (Figure $1)$. The first patient was died before our investigation at on age of seven years. The other two boys: the patient 2 was diagnosed at the age of three years when he was operated for inguinal hernia. Coarse facial feature including macrocrania, macroglossia and small teeth and poorly implemented were noted at an age of eighteen months. He had a short stature (-4DS), hepatosplenomegaly, skeletal disease and he had developed progressive mental retardation. Then, he deceased as a result of cardiorespiratory disease. The patient 3 was developed similar coarse facial features at the age of eighteen months. He showed severe developmental delay, hydrocephaly, deafness and inguinal hernia.

The MPS II patients were offspring of consanguineous marriage between first cousins (Figure 1). Blood samples were collected from the patients, their parents, and

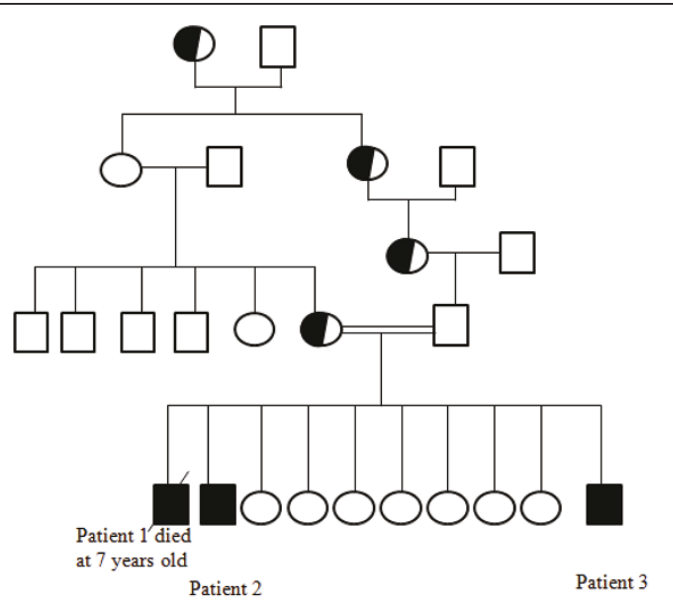

Figure 1 Pedigree of studied family. Square and circles indicate male and female members, respectively. Shaded symbols indicate affected individuals.

unaffected siblings and relatives. The clinical diagnosis was confirmed enzymatically (Table 1 ). This study was approved by the Ethnics Committees of the Tunisian Hospital and the parents gave full informed consent.

\section{IDS activity and Mutation analysis}

IDS activity was determined in sonicated leukocytes pellets as described using the artificial substrate 4-methylumbelliferyl-alpha-iduronide-2-sulfate [12]. For IDS mutation analysis, genomic DNA was extracted from peripheral blood leukocytes by the phenol-chloroform procedure. Each of the 9 exon and intron-exon boundaries of IDS gene were amplified from genomic DNA from the patient and her parents as described previously [13]. The typical PCR reaction was carried out in a 50 $\mu \mathrm{l}$ total volume containing $100 \mathrm{ng}$ of genomic DNA, 0.2 $\mathrm{mmol} / \mathrm{L}$ dNTPs, $0.4 \mu \mathrm{M}$ of each primer, $1.5 \mathrm{mmol} / \mathrm{L}$ $\mathrm{MgCl}_{2}, 10 \%$ (V/V) DMSO and $0.15 \mu \mathrm{l}$ (0.75 units) of Taq polymerase (Bromega).

\section{Results}

Clinical findings: the clinical features of MPS II patients and their leukocyte IDS activity are presented in Table 1.

\section{IDS mutation analysis}

The patients from southern Tunisia were homozygous for a $\mathrm{G}$ to $\mathrm{C}$ transversion in exon 3 predicting an arginine to a proline missense mutation p.R88P. In addition, five sequence variants, including four previously reported polymorphisms, were detected. The unreported polymorphisms was IVS7+38 (c.1006+38T > C). The previously described polymorphisms were IVS3-16 (c.419-16 delT), T146T (c.438 C > T), T214M (c.641C > T), IVS5-87(c.709-87G > A) (Table 2). 
Table 1 the clinical features of MPS II patients and their leukocyte IDS activity

\begin{tabular}{lll}
\hline Features & Patient $\mathbf{1}$ & Family $\mathbf{1}$ \\
\hline MPS II genotype & P.R88P & Patient $\mathbf{~}$ \\
\hline IDS activity nmol/h/mg protein & 2 & 5 \\
\hline Prenatal diagnosis & $1^{\text {st }}$ cousins & $1^{\text {st }}$ cousins \\
\hline Age at diagnosis (year/month) & 3 years & 3 years \\
\hline Age of onset (year/month) & 18 months & 18 months \\
\hline Sex & Male & Male \\
\hline Growth retardation & Marked & Marked \\
\hline Macroglossia & Marked & Marked \\
\hline Macrocarinia & Marked & Marked \\
\hline Hepatosplenomegaly & Marked & Marked \\
\hline skeletal deformities & severe & severe \\
\hline Other features & teeth small and poorly located deafness & teeth small and poorly located deafness \\
\hline Mental retardation & severe & severe \\
\hline IDS activity nmol/h/mg protein & 2 & 5 \\
\hline
\end{tabular}

\section{Discussion}

Estimates of the incidence of MPS II in European and Anglo-Saxon countries range from 1:55 000 to 1:160 250 male newborns [14-20]. It is the most common type of MPS in Taiwan and northern Asia [21,22].

In Tunisia, the global incidence of all the MPS is 2.3/ 100.000 lives births [23]. A prevalence of different types of mucopolysaccharidoses was evaluated as the MPS type I, III and IV [24] but that of type II is unknown due the ignorance of some clinical picture.

Furthermore, MPS II is expected to be found only in males, but some females have been reported [25,26].

The diagnosis of MPS II patients was made by demonstrating an increased amount of urinary heparan sulfate and dermatan sulfate, and very low residual IDS activity in peripheral blood leukocytes.

According to the HGMD database, to date, more than 300 different mutations in the IDS gene had been reported in patients with Hunter syndrome (Human Gene Mutation Database; http://www.hgmd.org). The mutational spectrum associated with the IDS gene is quite heterogeneous and ranges from point mutations to large-scale gene conversion or deletion. The majority of mutations are missense and nonsense mutation, and approximately $15 \%$ of mutations are presumed to be caused by a gross deletion.

This study identified the first IDS mutation in Tunisian patients with the Hunter syndrome. These patients, whose were born to consanguineous parents, were homozygous for the previously described p.R88P missens mutation [27]. The p.R88P mutation resulted in the replacement of a basic arginine with a neutral proline. A non conservative substitution could be predicted to drastically change the orientation of the secondary structure in IDS protein. This mutation causes a sever instability or loss of IDS protein function leading to a severe disease.

Homology analyses revealed that arginine- 88 is highly conserved among the human and eukaryotic sulfatases (Figure 2). The structure of human IDS was modeled by homology with crustal structure of human N-actylgalactosamine-4-sulfatase (4S) and arysulfatase A (ASA)

Table 2 Mutation and polymorphisms in MPS II patient

\begin{tabular}{|c|c|c|c|c|c|c|c|c|}
\hline Mutation & Nucleotide change & Position cDNA & Codon & Exon/Intron & References & polymorphisms & Exon/intron & References \\
\hline & & & & & & $\begin{array}{l}\text { IVS3-16 } \\
\text { c.419-16 delT }\end{array}$ & 4 & \\
\hline & & & & & & $\begin{array}{l}\text { T146T } \\
\text { c.438 C > T }\end{array}$ & 4 & {$[31]$} \\
\hline \multirow[t]{3}{*}{ p.R88P } & $G>C$ & 263 & 88 & 3 & {$[28]$} & $\begin{array}{l}\text { T214M } \\
\text { c.641 C > T }\end{array}$ & 5 & \\
\hline & & & & & & $\begin{array}{l}\text { IVS5-87 } \\
\text { C.709-87 G > A }\end{array}$ & 6 & \\
\hline & & & & & & $\begin{array}{l}\text { IVS7+38 } \\
\text { C. } 1006+38 T>C\end{array}$ & 7 & This report \\
\hline
\end{tabular}


[28]. Therefore, residue 88 appears to be not essential for processing but important for IDS conformation [29]. $\mathrm{R} 88$ residue is found adjacent to the active site residue, C84, and is a part of the core of the major domain of IDS. The alteration by proline, a more bulky hydrophobic residue, can affect the stability of the major domain structure. The side-chain of R88 stretches in the opposite direction from the active site and arginine has a hydrophobic root in its side-chain. Thus, the substitution of R88 by a smaller hydrophobic residue, proline, could be tolerated (Figure 3).

In the present study, five IDS sequence variants (IVS316 (c.419-16 delT), T214M (c.641C > T), T146T (c.438 C > T), IVS5-87(c.709-87G > A). have been identified in Tunisian MPS II patients, including one novel polymorphism (IVS7+38 (c.1006+38T > C). Since the T146T substitution has frequently been described as a polymorphism site [30]. This modification was identified in homozygous state in patient with a severe phenotype [31] and also in patient with mild phenotype [13]. Our

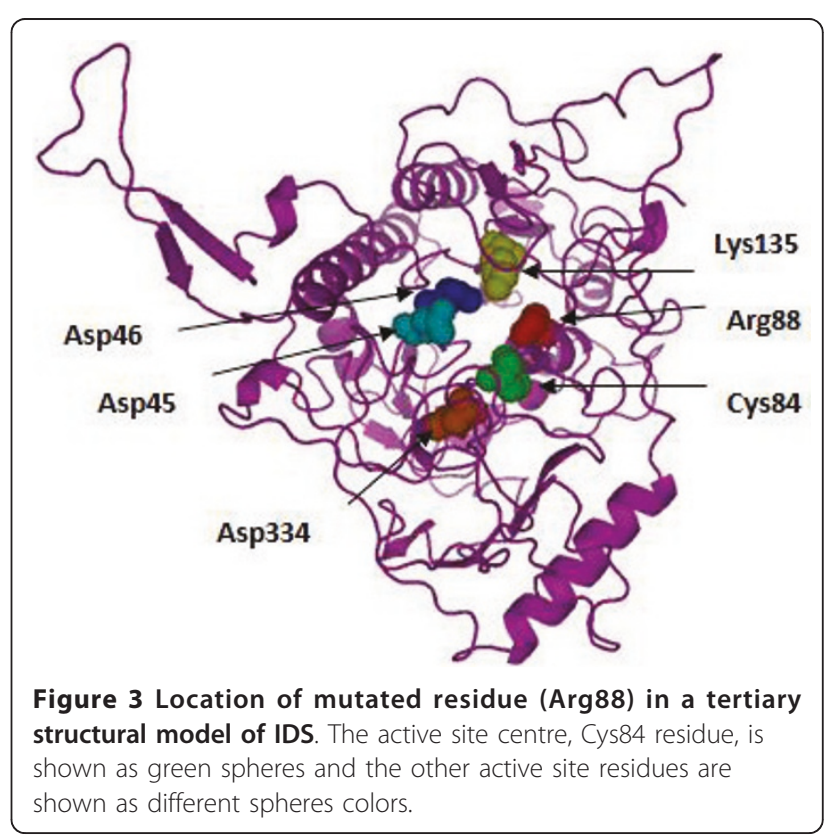


study showed that this modification was associated with a previously reported p.R88P mutation and others described polymorphisms and unreported polymorphism.

The effect of these polymorphisms on the expression of IDS is unknown. Further studies on large number of MPS II patients and normal population might help in finding out whether these variants are associated with MPS II or not. Moreover, the correlation between genotype and phenotype has remained unclear.

We note a considerable heterogeneity of MPS I [32] and MPS IVA [33] mutations in Tunisia; we also estimate that more mutations could be potentially present in the population.

The identification of a large battery of mutations in MPS patients including MPS I, MPS II and MPS IVA patients and the possibility of their early detection represent a cornerstone for the establishment of MPS prevention program in Tunisia based on prenatal diagnosis.

\section{Conclusion}

In conclusion, this is the first report of IDS mutation in Tunisian patients with MPS II. We applied the following strategy: An accurate biochemical test is available for the diagnosis of Hunter disease consisting of the demonstration on deficient IDS activity in leucocytes. This test was performed before molecular analysis. Molecular identification of the mutation in individuals with a confirmed diagnosis can be used for carrier detection of the females in family at risque and prenatal diagnosis.

\section{Consent}

Written informed consent was obtained from the patient for publication of this case report and accompanying images. A copy of the written consent is available for review by the Editor-in-Chief of this journal.

\section{List of abbreviations}

MPS II: Mucopolysaccharidosis II; IDS: Iduronate -2-sulfatase; PCR: polymerase chain reaction; MPS I: mucopolysaccharidosis I; MPS IVA: mucopolysaccharidosis IVA.

\section{Acknowledgements}

We thank so much Dr Froissart Roseline and Dr Christine Vianey-Saban for their active collaboration in this work.

\footnotetext{
Author details

${ }^{1}$ Biochemistry Laboratory Farhat Hached Hospital, 4000 Sousse, Tunisia. ${ }^{2}$ Biology Molecular Laboratory University of Pharmacy, 5000 Monastir, Tunisia. ${ }^{3}$ Hereditary service of metabolic diseases and neonatal screening. Center of biology and pathology. 69677 BRON CEDEX, France.
}

\section{Authors' contributions}

LC, SK and RT have done all the work (PCR, sequencing...) in the laboratory. SF, RF and HC analysis the results. CH VC, SL and AM has given final approval of the version to be published. All authors read and approved the final manuscript.

\section{Competing interests}

The authors declare that they have no competing interests.

Received: 4 April 2011 Accepted: 23 May 2011 Published: 23 May 2011

\section{References}

1. Neufeld EF, Muenzer J: The mucopolysaccharidoses. In The metabolic basis of inherited disease.. 6 edition. Edited by: Scriver CR, Beaudet AL, Sly WS, Valle D. McGraw-Hill, New York; 1989:1565-1588.

2. Elizabeth JR, McKinnis BA, Sulzbacher Stephen PhD, Joe C, Rutledge MD, Jean Sanders MD, Scott C, Ronald MD: Bone marrow transplantation in Hunter syndrome. Pediatrics 1990, 85:1092-102.

3. Muenzer J, Lamsa JC, Garcia A, Dacosta J, Garcia J, Treco DA: Enzyme replacement therapy in mucopolysaccharidosis type II (Hunter syndrome): a preliminary report. Acta Pñdiatr Suppl 2002, 439:98-99.

4. Wilson PJ, Suthers GK, Callen DF, Baker E, Nelson PV, Cooper A, Wraith JE, Sutherland GR, Morris CP, Hopwood JJ: Frequent deletions at Xq28 indicate genetic heterogeneity in Hunter syndrome. Hum Genet 1991, 86:505-508.

5. DiNatale $P$, Ronsisvalle L: Identification and partial characterization of two enzyme forms of iduronate sulfatase from human placenta. Biochim Biophys Acta 1981, 661:106-111.

6. Bielicki J, Freeman C, Clements PR, Hopwood JJ: Human liver iduronate-2sulphatase: purification, characterization and catalytic properties. Biochem J 1990, 271:75-86.

7. Wilson PJ, Morris CP, Anson DS, Occhiodoro T, Bielicki J, Clements PR, Hopwood JJ: Hunter syndrome: isolation of an iduronate-2-sulfatase cDNA clone and analysis of patient DNA. Proc Nat Acad Sci 1990, 87:8531-8535.

8. Ricci V, Filocamo M, Regis S, Corsolini F, Stroppiano M, Di Duca M, Gatti R. Expression studies of two novel in cis-mutations identified in an intermediate case of Hunter syndrome. Am J Med Genet 2003, 120A:84-87.

9. Bondeson ML, Dahl N, Malmgren H, Kleijer WJ, Tonnesen T, Carlberg BM, Pettersson U: Inversion of the IDS gene resulting from recombination with IDS-related sequences is a common cause of the Hunter syndrome. Hum Molec Genet 1995, 4:615-621.

10. McKusick VA: The Mucopolysaccharidoses. Heritable Disorders of Connective Tissue. 4 edition. St. Louis: C. V. Mosby; 1972, 556-574.

11. Chaabouni $M$, Ben Slimen $M$, Boudawara $M$, Ben Amar H, Mahfoudh A, Ayadi F, Ben Halima N, Hachicha M, Karaay A, Triki A: Mucopolysaccharidoses in children. Experience of a general pediatric service 11 cases. Tunis Med 2001, 79:222-300.

12. Voznyi $\mathrm{YV}$, Keulemans $\mathrm{J}$, van Diggelen OP: A fluorimetric enzyme assay for the diagnosis of MPS II (Hunter disease). J Inherit Metab Dis 2001, 24:675-80

13. Mirella F, Gloria B, Fabio C, Raffaella M, Roberto C, Rosanna G: Molecular Analysis of 40 Italian Patients With Mucopolysaccharidosis Type II: New Mutations in the Iduronate-2-sulfatase (IDS) Gene. Hum Mutat 2002.

14. Applegarth D, Toone JR, Lowry RB: Incidence of inborn errors of metabolism in British Columbia, 1969-1996. Pediatrics 2000, 105:1-6.

15. Machill G, Barbujani G, Danieli GA, Hermann FH: Segregation and sporadic cases in families with Hunter_s syndrome. J Med Genet 1991, 28:398-40.

16. Meikle PJ, Hopwood JJ, Clague AE, Carey WF: Prevalence of lysosomal storage disorders. JAMA 1999, 281:249-254.

17. Nelson J: Incidence of mucopolysaccharidoses in Northern Ireland. Hum Genet 1997, 101:355-358.

18. Nelson J, Crowhurst J, Carey B, Greed L: Incidence of the mucopolysaccharidoses in Western Australia. Am J Med Genet 2003, 123A:310-31.

19. Poorthuis BJHM, Wevers RA, Kleijer WJ, Groener JE, de Jong JG, van Weely S, Niezen-Koning KE, van Diggelen OP: The frequency of lysosomal storage diseases in The Netherlands. Hum Genet 1999, 105:151-15.

20. Young ID, Harper PS: Incidence of Hunter's syndrome. Hum Genet 1982, 60:391-392.

21. Lin HY, Lin SP, Chuang CK, Niu DM, Chen MR, Tsai FJ, Chao MC, Chiu PC, Lin SJ, Tsai LP, Hwu WL, Lin JL: Incidence of the mucopolysaccharidoses in Taiwan, 1984-2004. Am J Med Genet 2009, 149A:960-964.

22. Lin SP, Chang JH, Lee-Chen GJ, Lin DS, Lin HY, Chuang CK: Detection of hunter syndrome (mucopolysaccharidosis type II) in Taiwanese: Biochemical and linkage studies of the iduronate-2-sulfatase gene defects in MPS II patients and carriers. Clinica Chimica Acta 2006, 29-34. 
23. Laradi S, Monastiri K, Ferchichi S, Nabli N, Aouini Rea P, Ben Limam H, Miled A: Clinical, biological and molecular study of mucopolysaccharides in central and southTunisia. Ann Biol Clin 2001, 59:100-4.

24. Ben Turkia H, Tebib N, Azzouz H, Abdelmoula MS, Ben Chehida A, Chemli J, Monastiri K, Chaabouni M, Sanhagi H, Zouari B, Kaabachi N, Ben Dridi MF: Incidence of mucopolysaccharidoses in Tunisia. Tunis Med 2009, 87:782-785.

25. Broadhead DM, Kirk JM, Burt AJ, Gupta V, Ellis PM, Besley GT: Full expression of Hunter's disease in a female with an X-chromosome deletion leading to non-random inactivation. Clin Genet 1986, 30:392-398.

26. Clarke JTR, Pearce RD, Greer WL, Strasberg P, Ray PN: Hunter disease (MPS, type II) in a karyotypically normal girl associated with selective Xchromosome inactivation. Am J Hum Genet 1990, 47.

27. Balzano N, Villani GR, Grosso M, Izzo P, Di Natale P: Detection of four novel mutations in the iduronate-2-sulfatase gene. Mutations in brief. Hum Mutat 1998, 11:333.

28. Chi HK, Hye ZH, Seng MS, Kyung HP, Eun KK, Kwang BM, Jeong HY, Cheol KH, Dong KJ: Mutational Spectrum of the Iduronate 2 Sulfatase Gene in 25 Unrelated Korean Hunter Syndrome Patients: Identification of 13 Novel Mutations. Hum Mutat 2003, 599.

29. Villani GRD, Daniele A, Balzano N: Expression of five iduronate-2-sulfatase site-directed mutations. Biochimica et Biophysica Acta 2000, 1501:71-8.

30. Hopwood JJ, Bunge S, Morris CP, Wilson PJ, Steglich C, Beck M, Schwinger $E$, Gal A: Molecular basis of mucopolysaccharidosis type II: mutations in the iduronate-2-sulfatase gene. Hum Mutat 1993, 2:435-442.

31. Flomen RH, Green PM, Bentley DR, Giannelli F, Green EP: Detection of point mutations and a gross deletion in six Hunter syndrome patients. Genomics 1992, 13:543-550

32. Chkioua L, Khedhiri S, Kassab A, Bibi A, Ferchichi S, Froissart R, VianeySaban C, Laradi S, Miled A: Molecular analysis of mucopolysaccharidosis type I in Tunisia: identification of novel mutation and eight Novel polymorphisms. Diagn Pathol 2011, 6:39.

33. Khedhiri S, Chkioua L, Ferchichi S, Miled A, Laradi S: Polymorphisms in Tunisian patients with $\mathrm{N}$-acetylgalactosamine-6-sulfate sulfatase gene deficiency: Implication in Morquio A disease. Diagn Pathol 2011, 6:11.

doi:10.1186/1746-1596-6-42

Cite this article as: Chkioua et al: Molecular analysis of iduronate -2sulfatase gene in Tunisian patients with mucopolysaccharidosis type II. Diagnostic Pathology 2011 6:42.

\section{Submit your next manuscript to BioMed Central and take full advantage of:}

- Convenient online submission

- Thorough peer review

- No space constraints or color figure charges

- Immediate publication on acceptance

- Inclusion in PubMed, CAS, Scopus and Google Scholar

- Research which is freely available for redistribution

Submit your manuscript at www.biomedcentral.com/submit
Biomed Central 